\title{
Time budgets and at-sea behaviour of lactating female Antarctic fur seals Arctocephalus gazella at Bouvetøya
}

\author{
Martin Biuw $^{1, *}$, Bjørn A. Krafft ${ }^{2}$, G. J. Greg Hofmeyr ${ }^{3,4}$, Christian Lydersen ${ }^{1}$, \\ Kit M. Kovacs ${ }^{1}$ \\ ${ }^{1}$ Norwegian Polar Institute, Polar Environmental Centre, 9296 Tromsø, Norway \\ ${ }^{2}$ Institute of Marine Research, PO Box 1870 Nordnes, 5870 Bergen, Norway \\ ${ }^{3}$ Mammal Research Institute, Department of Zoology and Entomology, University of Pretoria, Pretoria 0002, South Africa \\ ${ }^{4}$ Present address: Port Elizabeth Museum at Bayworld, PO Box 13147, Humewood 6013, Port Elizabeth, South Africa
}

\begin{abstract}
We present the first data on attendance patterns, at-sea movements and diving behaviour of Antarctic fur seals breeding at Bouvetøya (Bouvet Island), Southern Ocean. While other colonies have been extensively studied, this remote and second largest global population remains relatively unknown. Time depth recorders and satellite relay data loggers were deployed on breeding females during the 2000-2001 and 2001-2002 summers. Attendance and foraging patterns were similar to those observed at colonies in the Scotia Sea region where Antarctic krill Euphausia superba is the predominant prey. Early to mid-lactation trips ranged within $\sim 100 \mathrm{~km}$ of the island, usually towards the west; the dominant direction shifted later in the season and the range also increased markedly to a peak between early February and early March. Solar elevation influenced arrivals and departures from the island, with most departures occurring around sunset. Diurnal variations in diving behaviour were consistent with the vertical migration of krill. Diving frequency was higher at night and diving effort peaked around morning twilight. Afternoon deep diving was common, suggesting that females might target dense daytime krill aggregations between the photic zone and the thermocline. Trip durations increased throughout early to mid-lactation, peaking in late January to early March, before again decreasing towards the end of lactation. Our results illustrate the substantial variability, both between individuals and within individuals over time, that is likely to reflect variations in prey distribution and in the growth requirements of pups. Such variations need to be taken into account when estimating habitat use and resource utilisation in marine top predators.
\end{abstract}

KEY WORDS: Foraging ecology · Krill predator · Diving · Satellite tracking · TDRs · Otariids · Southern Ocean

\section{INTRODUCTION}

The Southern Ocean ecosystem is generally characterised by relatively short food webs with a few key components. One such key component is Antarctic krill Euphausia superba, and over the past decades a considerable number of studies have been carried out to monitor this key species and the predators depending on it for their survival (see references in Kock
2000). While extensive studies on some key populations of krill-dependent predators have provided data on many of the input parameters required for ecosystem-based management models (Hill et al. 2007), other populations have received much less attention. The isolated island of Bouvetøya is the only landmass within subarea 48.6 defined by the Convention for the Conservation of Antarctic Marine Living Resources (CCAMLR). Sporadic expeditions to the island in re- 
cent decades have collected basic data on population size, reproductive performance and diet of krill predators following the methods of the CCAMLR Ecosystem Monitoring Program (CEMP) (Klages et al. 1999, Kirkman et al. 2000, 2001, Hofmeyr et al. 2005). The island is a CEMP network site for the monitoring of Antarctic fur seals Arctocephalus gazella, chinstrap penguins Pygoscelis antarcticus and macaroni penguins Eudyptes chrysolophus. However, no published studies to date have described attendance patterns, at-sea movements, habitat preference or feeding behaviour of any of the CEMP predator species from Bouvetøya.

Antarctic fur seals are arguably the best studied otariid. Long-term studies of attendance patterns, time budgets and reproductive performance and how these variables change with environmental fluctuations have provided the basis for the selection of parameters for CEMP (Reid et al. 2005). The exact way in which individuals from different populations allocate their time and energy will be strongly influenced by local conditions, and many studies have described substantial variations especially in terms of the duration and range of at-sea feeding trips during lactation. Models using energy as a currency have also been developed to explain observed patterns of attendance, trip durations and pup growth rates in terms of maximisation of the rate of energy transfer from mothers to pups (Boyd 1998, 1999, Trillmich \& Weissing 2006, Houston et al. 2007).

Variations in trip durations and attendance patterns over the lactation period have been examined frequently using radio telemetry (e.g. Boyd et al. 1991, Staniland et al. 2004) or visual observation of individually marked animals (e.g. Goldsworthy 1995), and have often been analysed in relation to individual at-sea movements and diving behaviour. These parameters have been examined in combination with growth rates of mothers and pups as measures of the profitability of various strategies. However, data have usually been summarised for an individual over an entire period of observation, covering several feeding trips (Lunn et al. 1993). Few studies describe individual changes in these patterns throughout lactation, or how maternal behaviour patterns are correlated with the growth rates of individual pups (Goldsworthy 1995). In some studies dive recorders and satellite relay data loggers (SRDLs) have been deployed for short durations at different time periods of lactation, usually cross-sectionally, on different individuals (Beauplet et al. 2004).

In our paper we present data from the first studies using satellite telemetry and dive recorders on lactating Antarctic fur seal females at Bouvetøya. We describe the attendance patterns and diving behaviour of 16 individuals equipped with dive recorders throughout the initial 5 to $6 \mathrm{wk}$ of lactation. In addition, we describe attendance patterns, at-sea movements and diving behaviour from 6 mothers equipped with SRDLs over the entire lactation period and through until late autumn/early winter. We use these longitudinal records to examine the variability in at-sea behaviour and attendance patterns between individuals and also within individuals as the lactation period progresses.

\section{MATERIALS AND METHODS}

We selected Antarctic fur seal mothers with newborn pups from the main breeding colony at Nyrøysa $\left(54.41^{\circ} \mathrm{S}, 03.29^{\circ} \mathrm{E}\right)$ during the period of peak pupping in mid-December (Table 1). We selected only females with newborn pups for the present study. We assumed that the presence of an umbilicus and, in a minority of cases, small pup size and naïve pup behaviour, indicated that mothers were still in their perinatal period between pupping and departing on their first trip to sea. We captured and manually restrained adult female seals in a large cone-shaped hoop net $(1.5 \mathrm{~m}$ long $\times 1 \mathrm{~m}$ diameter) attached to an aluminium frame and handle (see David et al. 1990 for further description). We weighed mothers to the nearest $\mathrm{kg}$ prior to instrument attachment by briefly suspending them in the hoop net attached to a mechanical spring scale (Salter ) on a pole held between 2 researchers. We also weighed their pups to the nearest $0.1 \mathrm{~kg}$ by suspending them briefly in a canvas bag attached to a mechanical spring scale. We measured standard body length and axial girth on most instrumented females (Committee on Marine Mammals 1967) before gluing instruments to the fur of the mid-dorsal region using 2 component quick-setting marine epoxy (5-Cure, Industrial Formulators).

We deployed 6 SRDLs (Sea Mammal Research Unit, St. Andrews, UK) and 16 Mk6 time depth recorders (TDRs; Wildlife Computers) during the first period of the 2000-2001 and 2001-2002 seasons. We inspected instrument attachments regularly when females were present on the colony, and re-glued them if needed. We removed TDRs after 5 to $6 \mathrm{wk}$, prior to the expedition's departure from the island, while SRDLs fell off naturally during the annual moult (Table 1). In the 2000-2001 season, all 3 SRDLs were deployed on 17 December, while in the 2001-2002 season, the 3 deployments were carried out on 14 December (Table 1).

The SRDL dimensions were $10.5 \times 7.0 \times 3.5 \mathrm{~cm}$, and they weighed $400 \mathrm{~g}$ in air. The weight in water (assuming a water density of $1.028 \mathrm{~g} \mathrm{~cm}^{-1}$ ) was $\sim 135 \mathrm{~g}$. These weights represent approximately 1.0 and $0.3 \%$ of the body mass of female fur seals in air and water respectively. The frontal surface area of the SRDLs was $24.5 \mathrm{~cm}^{2}$, representing about $4.5 \%$ of the frontal sur- 
Table 1. Arctocephalus gazella. Deployment and recovery statistics for Antarctic fur seals equipped with satellite relay data loggers (SRDLs) and Mk6 time depth recorders (TDRs) at Bouvetøya in 2000-2001 and 2001-2002. SRDLs were re-glued as needed prior to the field team's departure from the island, and left attached until they fell off naturally during the annual moult. Body length was measured as Standard Length (STL), i.e. straight line from tip of the snout to tip of the tail. na = not available

\begin{tabular}{|c|c|c|c|c|c|c|c|c|}
\hline \multirow{2}{*}{$\begin{array}{l}\text { Date } \\
\text { deployed }\end{array}$} & \multirow[t]{2}{*}{ Seal ID } & \multirow{2}{*}{$\begin{array}{c}\text { Track } \\
\text { duration (d) }\end{array}$} & \multicolumn{2}{|c|}{ Body mass (kg) } & \multicolumn{2}{|c|}{ Body length (cm) } & \multicolumn{2}{|c|}{ Axial girth (cm) } \\
\hline & & & Deploy & Recap & Deploy & Recap & Deploy & Recap \\
\hline \multicolumn{9}{|l|}{ SRDL } \\
\hline \multirow[t]{3}{*}{2000 Dec 17} & bv1-1553-00 & 116 & 35 & 32 & 116 & na & 75 & 76 \\
\hline & bv1-22497-00 & 123 & 36 & na & 120 & na & 86 & 82 \\
\hline & bv1-2848-00 & 112 & 39 & 35 & 113 & na & 90 & 73 \\
\hline \multirow[t]{3}{*}{2001 Dec 14} & bv2-28489-01 & 167 & 42 & 33 & 107 & 110 & 91 & 76 \\
\hline & bv2-28490-01 & 167 & 43 & 37 & 113 & 103 & 78 & 79 \\
\hline & bv2-28491-01 & 150 & 53 & 39 & 121 & 113 & 94 & 84 \\
\hline \multicolumn{9}{|l|}{ TDR } \\
\hline \multirow[t]{2}{*}{2000 Dec 18} & bv1-003-00 & 50 & 41 & 42 & 126 & na & 99 & 89 \\
\hline & bv1-024-00 & 43 & 27 & 29.5 & 106 & na & 81 & 72 \\
\hline \multirow[t]{2}{*}{ Dec 19} & bv1-033-00 & 45 & 32 & 33 & 109 & na & 97 & 75 \\
\hline & bv1-043-00 & 47 & 27 & 25 & 106 & na & 82 & 73 \\
\hline \multirow[t]{4}{*}{ Dec 20} & bv1-052-00 & 43 & 29 & 28 & 98 & na & 82 & 72 \\
\hline & bv1-061-00 & 44 & 35 & 36 & 113 & na & 87 & 72 \\
\hline & bv1-073-00 & 41 & 34 & 34 & 112 & na & 85 & 75 \\
\hline & bv1-083-00 & 48 & 32 & 37 & 107 & na & 94 & 84 \\
\hline \multirow[t]{3}{*}{ Dec 21} & bv1-092-00 & 40 & 37 & 34 & 102 & na & 89 & 84 \\
\hline & bv1-105-00 & 42 & 36 & 30 & 105 & na & 86 & 66 \\
\hline & bv1-113-00 & 20 & 36 & 32 & 99 & na & 90 & 78 \\
\hline \multirow[t]{6}{*}{2001 Dec 15} & bv2-587-01 & 40 & 34 & 32 & 99 & 105 & 83 & 80 \\
\hline & bv2-457-01 & 39 & 48 & 38 & 117 & 98 & 99 & 87 \\
\hline & bv2-479-01 & 39 & 38 & 31 & 109 & 97 & 85 & 80 \\
\hline & bv2-468-01 & 39 & 47 & 45 & 116 & 114 & 90 & 89 \\
\hline & bv2-966-01 & 39 & 36 & 38 & 95 & 98 & 85 & 82 \\
\hline & bv2-777-01 & 39 & 47 & 42 & 113 & 113 & 90 & 98 \\
\hline \multirow[t]{2}{*}{ Dec 16} & bv2-438-01 & 38 & 43 & 32.5 & 110 & 89 & 86 & 80 \\
\hline & bv2-550-01 & 43 & 42 & 35 & 104 & 110 & 86 & 81 \\
\hline \multirow[t]{2}{*}{ Dec 17} & bv2-999-01 & 41 & 44 & 34 & 113 & 103 & 93 & 73 \\
\hline & bv2-758-01 & 38 & 43 & 42 & 107 & 121 & 90 & 85 \\
\hline
\end{tabular}

face area of a female fur seal. The Mk6 TDR dimensions were $6.5 \times 3.5 \times 1.5 \mathrm{~cm}$, and they weighed $53 \mathrm{~g}$ in air ( 18 $\mathrm{g}$ in water), representing approximately 0.15 and $0.05 \%$ of the mass of female fur seals in air and water respectively. The Mk6 TDR frontal surface area was $5.25 \mathrm{~cm}^{2}$, representing about $1 \%$ of the frontal surface area of a female fur seal.

The SRDLs sampled depth every $4 \mathrm{~s}$ while diving, but due to transmission bandwidth constraints of the Argos system the dive records were compressed before transmission (see Fedak et al. 2001 for details). The onboard processor was set up to define a 'dive' as starting when the tag was wet and below $5 \mathrm{~m}$ for $8 \mathrm{~s}$, and ending when the tag either (1) returned to within $5 \mathrm{~m}$ of the surface or (2) became dry. TDRs sampled depth every $10 \mathrm{~s}$ while the tag was wet, with a depth resolution of $2 \mathrm{~m}$. Raw data files obtained from the TDRs were extracted using purpose-built software provided by the manufacturer (Dive Analysis, Zero Offset Correction, Minimum-Maximum-Mean, BINEX, and Merge; Wildlife Computers). We consid- ered any excursions from the surface to a depth of $\geq 4 \mathrm{~m}$ (i.e. twice the depth resolution of the instruments) as a dive.

We used the R language, version 2.7.0 (R Development Core Team 2008), for all statistical and numerical analyses. All times are in Universal Time Coordinated (UTC) to facilitate comparisons between data sets from the 2 instrument types, since the time biases due to east-west movements $(-1 \min 26 \mathrm{~s}$ to $+52 \min 17 \mathrm{~s}$ for SRDL seals) were unknown for seals equipped with TDRs. We used filtered tracks from SRDLs (McConnell et al. 1992) as input into all track-based analyses. For each trip, we calculated the circular weighted mean and variance in the bearings from the island for all positions in that trip. Positions were weighted according to a Gaussian kernel function of time, centred on the time point in the middle of the period between departure and return, with SD set to half the trip duration. This approach assumes more or less equal outward and inward travel times between the island and feeding areas, but the wide kernel ensures that the 
weighted mean value is likely representative of the overall bearing from the island during each trip. This weighting scheme does not take Argos location quality indexes into account, but because of the prior speed filtering, this is unlikely to have caused any significant biases to the mean bearings at the relatively coarse resolution of this analysis. We also calculated the maximum range, i.e. the most distant point reached in each trip, using great circle distances.

We used circular analysis of variance (CANOVA; Jammalamadaka \& SenGupta 2001) to examine the degree of consistency in the general directions of travel between and within individuals, and also between and within years. The response variable in this analysis was the radian of the weighted mean bearing, while the explanatory grouping variable was either seal ID or year. No methods are available for 2-way cANOVAs, so these 2 explanatory variables could not be included in the same analysis. To examine the individual, within-year and between-year variations in more detail, we carried out a series of Watson's 2 -sample $U^{2}$ tests for homogeneity between 2 samples. Each pairwise comparison between 2 individuals was carried out on 10000 bootstrap samples. In each bootstrap, observations were randomly drawn (with replacement) from each individual seal. Data are summarised as the percentage of the 10000 bootstraps that were significant at the $\mathrm{p}<0.001$ level. We also examined the consistency of trip mean bearings within individuals over time by comparing the weighted mean bearing in trip $t$ to a wrapped normal probability density function with mean and SD set to the weighted mean bearing and variance in trip $t-1$. We assumed that the mean bearing of trip $t$ was significantly different from that of trip $t-1$ if the probability density corresponding to this bearing was $<0.05$.

We used generalised additive mixed-effects models (GAMM; Wood 2004) to explore seasonal trends in trip duration. We included trip duration as a response variable and trip departure date as an explanatory variable. The advantage with GAMMs is that they combine the ability of linear mixed-effects models (LMEs) to allow for correlation between within-subject errors, i.e. in longitudinal data (e.g. Pinheiro \& Bates 2002), with the ability of GAMMs to model nonlinear relationships between explanatory and response variables (Gu \& Wahba 1991). We used individual as a random effect to account for the lack of independence between observations from the same individual, and we allowed the intercept and degree of smoothing to vary between individuals.

We examined the timing of departures from and arrivals to the colony in relation to time of day (UTC) as well as solar elevation. We fitted kernel densities to the distributions using a local polynomial kernel smoother
(Wand \& Ripley 2005). Algorithms for calculating solar elevation and time of sunrise and sunset were based on Meeus (1991), available in the R package maptools (Lewin-Koh \& Bivand 2008). We also examined the occurrence and maximum depth of dives in relation to solar elevation using similar methods.

We calculated summaries of total time spent diving and total time at the surface on a trip-by-trip basis, and compared these throughout the data records using GAMMs. The response variable was the ratio of time spent diving to time spent at the surface. Because data sets from the 2 instrument types used in the present study were different, we calculated this index separately for TDRs and SRDLs. In the case of TDRs we simply divided the sum of all periods spent at the surface by the sum of all dive durations, while for SRDLs we calculated the sum of all dive durations divided by the sum of all subsequent surface intervals. This second method does not account for all extended periods at the surface, since these periods are not recorded in relation to specific dives. These indexes should therefore be treated as relative rather than absolute; the analysis simply addresses changes over time rather than absolute trip time budgets.

Note on differences in data types. We have been cautious to keep the analyses of SRDL and TDR data separate as much as possible, and to make only general statements of differences or similarities between these. The different durations and sample sizes for the 2 data types makes common analyses problematic. However, in some analyses we have included animals with both types of instruments. To ensure that patterns from the 2 instrument types did not give rise to biases in these analyses, we compared the relevant parameters (e.g. trip duration, pup growth trajectories, female mass change) for the period where both data types were available, i.e. the first 5 to $6 \mathrm{wk}$, using LMEs.

\section{RESULTS}

\section{At-sea movements}

Data records from SRDLs ranged in duration from 112 to $167 \mathrm{~d}$ (mean $\pm \mathrm{SD}=139.2 \pm 25.3 \mathrm{~d})$. The number of consecutive trips between the island and offshore feeding areas ranged from 14 to 24 (mean $\pm \mathrm{SD}=19.2$ \pm 4.1 ). Trips made by individual females are shown in Fig. 1. Trips during early lactation were generally oriented towards areas in a sector between southwest and northwest from the island, and the maximum distances reached were relatively short $(<100 \mathrm{~km})$. While some individuals travelled in similar directions during consecutive trips, other individuals showed more variability (Fig. 2). The variation in weighted mean bear- 

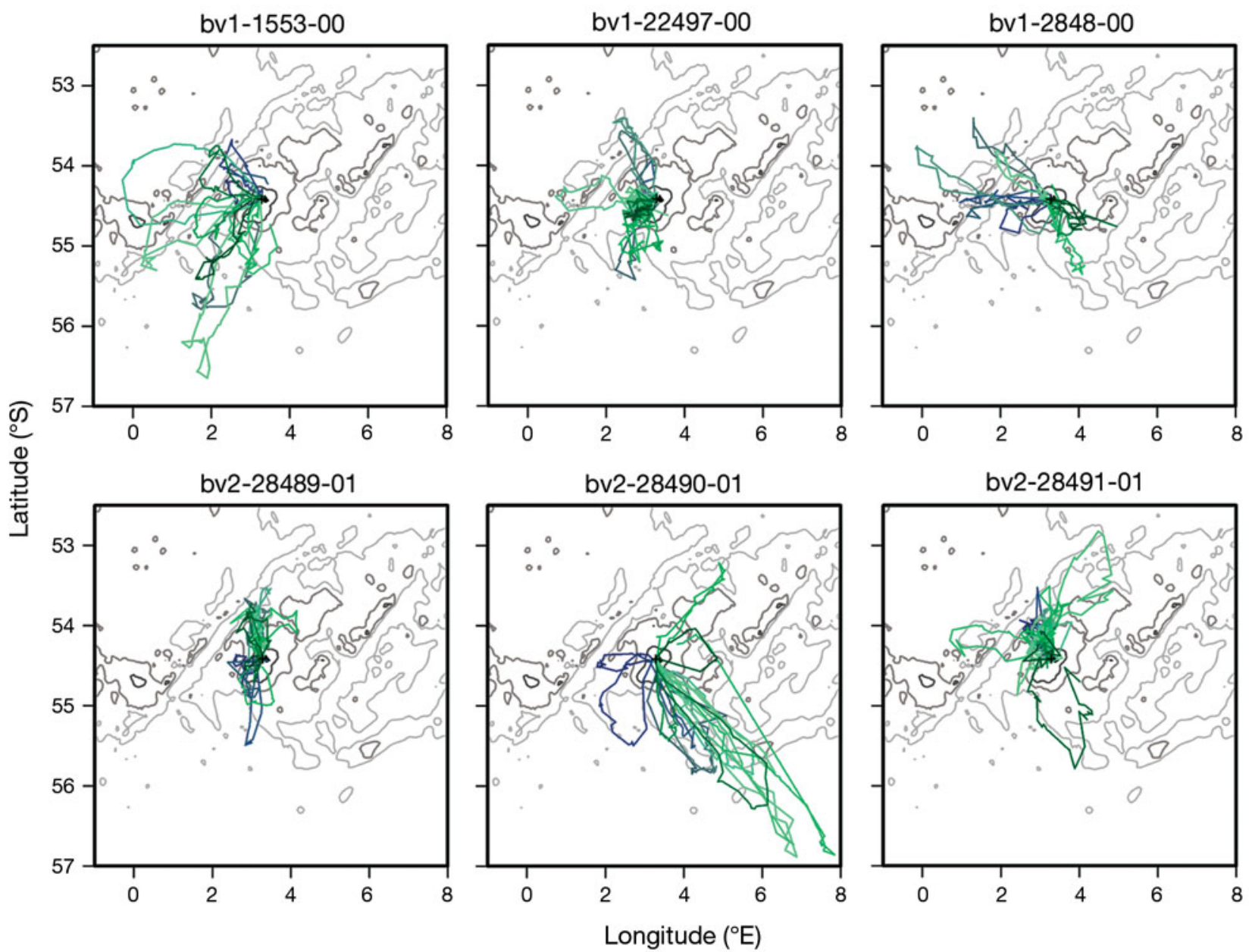

Fig. 1. Arctocephalus gazella. Argos tracks from 6 lactating fur seals equipped with satellite relay data loggers (SRDLs) at Bouvetøya in 2000 and 2001. The year of deployment is indicated by the last 2 digits in the seal ID number. The colours of tracks represent time from initial deployment, ranging from dark blue via lighter colour shadings to dark green which represents later trips. Bouvetøya is indicated by + . Grey lines represent depth contours from $1000 \mathrm{~m}$ (dark grey line) to $3000 \mathrm{~m}$ (light grey line), taken from the ETOPO2v2 2 min gridded global relief data (www.ngdc.noaa.gov/mgg/fliers/01mgg04.html)

ings was greater between individuals than between trips for specific individuals (cANOVA: $F_{5,103}=25.47$, $\mathrm{p}<0.001$ ) and also between years compared to within years (cANOVA: $F_{1,107}=33.25, \mathrm{p}<0.001$ ). Trip mean bearings of individuals could be clearly distinguished in 2000-2001, while seals in 2001-2002 were more similar (Table 2). In 2000-2001, all 3 seals initially travelled to feeding areas towards the west and northwest. Two of them (bv1-1553-00 and bv1-22497-00) showed relatively gradual trends towards more southerly trips during mid-lactation, which were interrupted by almost simultaneous, abrupt but transient, changes in general headings in early January. These changes coincided with increases in the maximum range within trips to approximately 200 to $250 \mathrm{~km}$. In contrast, the third seal (bv1-2848-00) gradually changed from overall westerly headings in early lactation towards northwesterly headings in late February, prior to a sig- nificant, abrupt change towards easterly and southeasterly headings that were maintained until the tag failed in early April (Fig. 2). The patterns in 2001- 2002 were more consistent between individuals as well as between trips for specific individuals, especially during early lactation. The early preference for westerly and northwesterly movements within $\sim 150 \mathrm{~km}$ was again evident, but these bearings were abandoned relatively early. From mid-January, 2 of the seals (bv228489-01 and bv2-28491-01) repeatedly (and almost synchronously) travelled northwards to areas about $100 \mathrm{~km}$ from Bouvetøya (Figs. 1 \& 2). These movements remained very consistent until early March when significant, abrupt changes in bearing and, in the case of 1 seal an abrupt increase in distance, occurred before the 2 seals once again settled into the pattern of northward migrations. The third seal (bv228490-01) also displayed remarkably consistent migra- 

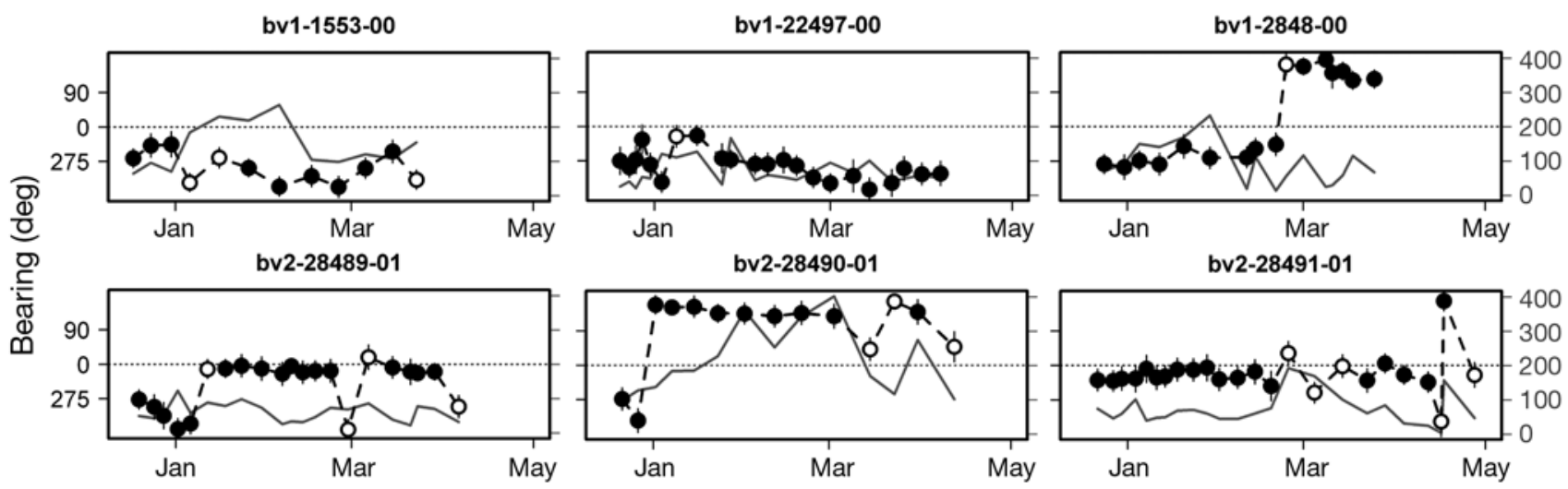

Fig. 2. Arctocephalus gazella. Weighted mean bearing ( and O) and maximum range (grey line) in consecutive trips by 6 female Antarctic fur seals during lactation in 2000-2001 and 2001-2002. Note that bearings are plotted from south (bottom) via north (middle) back to south (top), going around the compass clockwise. (O) Trips with a weighted bearing that deviate significantly from that of the previous trip

tion bearings during early to mid-lactation, repeatedly travelling towards the southeast (Figs. 1 \& 2), gradually increasing the maximum distances from Bouvetøya. The longest of these trips reached an area almost $400 \mathrm{~km}$ from the island. Abrupt changes in bearing were again observed in mid-March before the instrument terminated data transmission in mid-April.

\section{Attendance patterns and trip durations}

Foraging trip durations varied substantially, both between individuals and also for specific individuals

Table 2. Arctocephalus gazella. Summary of pairwise Watson's 2-sample test for homogeneity of trip mean bearings between pairs of seals. Values represent the percent of 10000 bootstraps (random samples selected from each individual with replacement) in which the individuals differed significantly at the $p<0.001$ level. (A) Percentage of pariwise comparisons with significant differences. (B) Summary statistics of percentages with significant differences between years, individuals and individuals within years

\begin{tabular}{|lrrrrr|}
\hline A & & & & \\
\hline bv1-22497-00 & 4.0 & & & \\
bv1-2848-00 & 12.2 & 22.5 & & & \\
bv2-28489-01 & 66.3 & 78.7 & 25.9 & & \\
bv2-28490-01 & 93.7 & 97.6 & 19.9 & 97.9 & \\
bv2-28491-01 & 99.6 & 86.8 & 94.4 & 7.4 & 100.0 \\
B & & & & Mean & SD \\
\hline Between years & & & & 73.7 & 30.6 \\
Between individuals & & & 60.5 & 39.5 \\
Between individuals & & 2000 & 12.9 & 9.3 \\
within years & & 2001 & 68.4 & 52.9 \\
\hline
\end{tabular}

over time (Table 3). Trips during the perinatal period were of relatively short duration (approx. 1 to $2 \mathrm{~d}$ ) but increased gradually thereafter (Fig. 3). Despite the substantial variation in individual time trends, some weak general patterns could also be observed. The increase over the first 2 to 3 mo was more rapid in 2000-2001 than in the following season. Maximum trip durations for SRDL seals of approximately 6 to $8 \mathrm{~d}$ were achieved in late January to early February (peak: 20 January; GAMM: $F_{4.28}=4.25, \mathrm{p}<0.001$ ), before durations decreased throughout February and stabilised at durations of around 4 to $5 \mathrm{~d}$ throughout March and April. There was substantial individual variation in overall location (represented by the intercept term) as well as the general shape of the fit (intercept $\mathrm{SE}=30.8$, smooth terms $\mathrm{SE}=286.7$, residual $\mathrm{SE}=$ 37.6). Similar patterns were observed for TDR seals in this season, but the short duration of data records prevented GAMM fitting. Maximum trip durations in the 2001-2002 season were of similar durations to those in 2000-2001, but appeared to occur much later in the season (peak: 6 March; GAMM: $F_{2.63}=3.76, \mathrm{p}<0.001$ ) and the subsequent decline was more rapid and without evidence of stabilisation, similar to that seen during the 2000-2001 season. This general pattern was also discernible in the changes in maximum trip range (Fig. 2). After a relatively sharp increase in maximum range over the initial month, all 3 SRDL seals in 2000-2001 showed almost simultaneous and rapid switches from long-ranging trips to short-ranging trips in mid-January, coincident with the decrease in trip durations. The decrease in trip duration and maximum range in 2001-2002 was more gradual and occurred later in the season. Again, individual variations accounted for a substantial proportion of the total variation (intercept $\mathrm{SE}=25.7$, smooth terms $\mathrm{SE}=91.1$, residual $\mathrm{SE}=32.7)$. 
Table 3. Arctocephalus gazella. Individual summary statistics for haulout and trip durations for seals equipped with satellite relay data loggers (SRDLs) and Mk6 time depth recorders (TDRs) in $2000\left(\mathrm{n}_{\mathrm{SRDL}}=3, \mathrm{n}_{\mathrm{TDR}}=8\right)$ and $2001\left(\mathrm{n}_{\mathrm{SRDL}}=3, \mathrm{n}_{\mathrm{TDR}}=7\right)$. Summaries are presented only for the first 5 to 6 wk of lactation for which both TDR and SRDL data were available

\begin{tabular}{|c|c|c|c|c|c|c|c|c|}
\hline \multirow[t]{2}{*}{ Seal ID } & \multicolumn{4}{|c|}{ — Haulout duration (h) — } & \multicolumn{4}{|c|}{ - Trip duration (h) } \\
\hline & Mean & Median & $\mathrm{SD}$ & $\mathrm{n}$ & Mean & Median & $\mathrm{SD}$ & $\mathrm{n}$ \\
\hline \multicolumn{9}{|l|}{ SRDLs } \\
\hline bv1-1553-00 & 54.8 & 56.5 & 10.4 & 13 & 136.5 & 144.5 & 63.0 & 6 \\
\hline bv1-22497-00 & 38.5 & 38.3 & 14.0 & 23 & 69.5 & 45.0 & 56.0 & 10 \\
\hline bv1-2848-00 & 59.4 & 46.0 & 41.4 & 17 & 104.4 & 119.1 & 40.6 & 5 \\
\hline bv2-28489-01 & 39.3 & 35.6 & 25.3 & 22 & 80.0 & 80.5 & 24.0 & 9 \\
\hline bv2-28490-01 & 64.7 & 66.0 & 37.3 & 15 & 116.3 & 117.8 & 14.6 & 6 \\
\hline bv2-28491-01 & 49.8 & 39.1 & 36.5 & 25 & 60.0 & 60.5 & 16.6 & 10 \\
\hline \multicolumn{9}{|l|}{ TDRs } \\
\hline bv1-003-00 & 29.1 & 30.6 & 10.8 & 8 & 76.8 & 50.1 & 70.9 & 9 \\
\hline bv1-024-00 & 41.1 & 46.9 & 10.6 & 5 & 113.3 & 118.1 & 37.3 & 6 \\
\hline bv1-033-00 & 27.4 & 28.9 & 6.5 & 9 & 67.7 & 68.1 & 17.8 & 10 \\
\hline bv1-043-00 & 40.4 & 25.0 & 36.4 & 10 & 46.9 & 18.7 & 62.3 & 11 \\
\hline bv1-052-00 & 27.7 & 19.8 & 19.6 & 10 & 46.6 & 37.2 & 27.3 & 11 \\
\hline bv1-073-00 & 35.5 & 31.0 & 14.7 & 7 & 62.3 & 48.4 & 53.7 & 8 \\
\hline bv1-092-00 & 34.4 & 35.5 & 12.9 & 6 & 85.8 & 76.1 & 27.9 & 7 \\
\hline bv1-113-00 & 96.3 & 96.3 & 38.2 & 2 & 18.4 & 22.2 & 10.2 & 3 \\
\hline bv2-468-01 & 21.5 & 23.7 & 9.8 & 11 & 46.4 & 53.7 & 22.4 & 12 \\
\hline bv2-438-01 & 28.0 & 27.1 & 11.0 & 8 & 53.7 & 48.2 & 40.0 & 9 \\
\hline bv2-479-01 & 33.2 & 25.0 & 27.9 & 6 & 78.0 & 70.5 & 33.6 & 7 \\
\hline bv2-587-01 & 30.0 & 27.9 & 16.1 & 6 & 89.6 & 111.0 & 39.0 & 7 \\
\hline bv2-758-01 & 30.4 & 31.2 & 11.1 & 8 & 64.8 & 60.4 & 19.4 & 9 \\
\hline bv2-777-01 & 31.1 & 31.1 & 0.7 & 2 & 80.1 & 80.1 & 15.1 & 2 \\
\hline bv2-999-01 & 37.8 & 36.1 & 14.0 & 6 & 84.3 & 78.7 & 22.8 & 7 \\
\hline
\end{tabular}

Attendance durations ashore decreased slightly following the perinatal period and then remained relatively constant in both years. This resulted in mothers spending proportionally less time suckling their pups as lactation progressed. TDR records again displayed a pattern similar to that observed for SRDLs. For the period of overlap between the 2 data types, there was no difference in trip duration trajectories between the 2 after the effects of individual (random effect for slope and intercept), date and year had been accounted for (LME: Duration Date+Instrument+Year, $t_{\text {Instrument }}=$ $-1.41, \mathrm{df}=19, \mathrm{p}=0.17$ ).

Arrivals to and departures from the colony did not occur randomly throughout the day. Most departures occurred between 15:00 and 21:00 h UTC (Fig. 4). This wide peak reflects the gradually decreasing day lengths during the long period of tracking, especially for the SRDLs (the period between sunrise and sunset decreased by about 2 to $3 \mathrm{~h}$ during the TDR deployments while it decreased by about $8 \mathrm{~h}$ during the SRDL deployments; Fig. 5). When departures were expressed as a function of solar elevations, there was a distinct peak occurring around or just before dusk; very few departures were observed at similar solar elevations around dawn. Arrivals to the colony were less clustered around a particular time or solar elevation. Arrivals were rare when the sun was $\geq 12^{\circ}$ below the horizon (i.e. the definition of nautical twilight; US Naval Observatory 2007), and most arrivals occurred during daylight hours, with weakly defined peaks around sunrise and sunset.

\section{Diving behaviour}

The total number of dives recorded for SRDLs and TDRs was 115519 (26384 and 89135 respectively). Despite the substantially longer data records from SRDLs, the number of dives recorded by each instrument was similar to the number obtained for the TDRs (approx. 5000 to 6000 dives). This is because data return from SRDLs is incomplete. SRDLs yielded records with $\sim 45$ dives $\mathrm{d}^{-1}$ while TDRs provided complete records with $\sim 160$ dives $\mathrm{d}^{-1}$, suggesting that data from $\sim 70 \%$ of dives recorded by SRDLs on Antarctic fur seals were not received by Argos. This is supported by a comparison of time spent diving in $6 \mathrm{~h}$ periods (which are based on the original complete data recorded, but not transmitted, by the SRDLs) with dive durations of all transmitted dives. This comparison shows that the total dive time based on transmitted dives represents $67.9 \pm 29.3 \%$ of the dive time based on $6 \mathrm{~h}$ summaries. The randomised strategy for selecting data for transmission incorporated in the onboard processing of the SRDLs ensures that this loss of data is unaffected by any daily variability on Argos uplink rates (Fedak et al. 2001).

The frequency of diving and the depths attained varied as a function of time of day, and were related to solar elevation (Fig. 5). This was especially evident from SRDL records where the track durations covered a range of light regimes from mid-summer to early winter. The high frequency of diving during the night peaked in the early morning hours before decreasing abruptly around sunrise (Figs. 5 to 7). Peak diving frequency generally coincided with the onset of nautical twilight at solar elevations of $-12^{\circ}$, and for the latter part of the SRDL records, this particular solar elevation appeared to trigger the abrupt decrease in diving activity.

Overall time budgets of seals are shown in Table 4. These time budgets varied substantially between indi- 


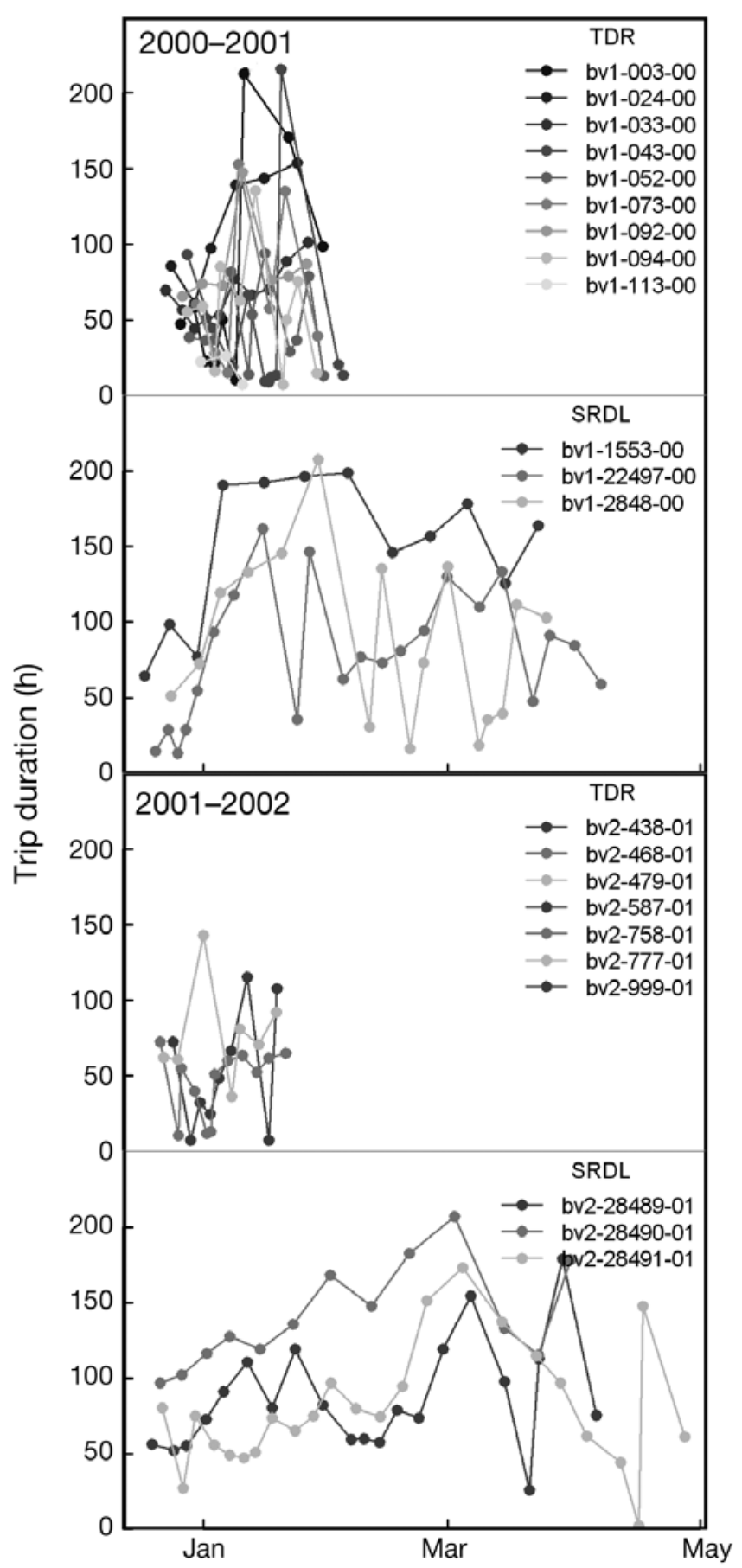

Fig. 3. Arctocephalus gazella. Trip duration plotted as a function of time for female Antarctic fur seals equipped with Mk6 time depth recorders (TDRs) or satellite relay data loggers (SRDLs) in each season, 2000-2001 (top) and 2001-2002 (bottom). The fitted curves represent predictions (mean $\pm \mathrm{SE}$ ) from generalised additive mixed-effects models (GAMM) of trip duration as a function of date

viduals. Diving made up the smallest proportion of the total time (mean $\pm \mathrm{SD}=9.9 \pm 3.5 \%$ ), while seals spent the majority of their time resting or swimming at the surface $($ mean $\pm \mathrm{SD}=55.3 \pm 9.5 \%$ ). Seals spent about $1 / 3$ of their time hauled out (mean $\pm \mathrm{SD}=34.8 \pm$ $11.1 \%)$. There was no difference in any of these proportions between seals equipped with TDRs and those carrying SRDLs (Wilcoxon tests: $W_{\text {haulout }}=62, \mathrm{p}=0.33$; $\left.W_{\text {surface }}=47, \mathrm{p}=0.97 ; W_{\text {dive }}=34, \mathrm{p}=0.33\right)$. The dive:surface time ratio within trips increased nonlinearly through early lactation $\left(\mathrm{GAMM}_{\mathrm{TDR}}: F_{2.286}=12.35\right.$, $\mathrm{p}<0.001$; GAMM $\left.\mathrm{SRDL}_{\text {L }} F_{4.033}=4.48, \mathrm{p}<0.001\right)$. While the indexes used for TDRs and SRDLs were different in magnitude because of the different nature of the data (range: 0.04 to 0.53 and 0.18 to 1.41 for TDRs and SRDLs respectively), the general trends were similar over the early lactation period (Fig. 8). For SRDLs, the ratio reached its maximum around the end of January, coinciding with the recovery of TDRs, and subsequently decreased gradually through the latter months of lactation, following a pattern very similar to that of trip durations (cf. Figs. $3 \& 8$ ). There were large individual variations in the exact timing and rate of change, as was evident from the substantial influence of the within-individual random effect in the GAMMS (TDRs: intercept $\mathrm{SE}=0.056$, smooth terms $\mathrm{SE}=0.089$, residual $\mathrm{SE}=0.062$; SRDLs: intercept $\mathrm{SE}=0.20$, smooth terms $\mathrm{SE}=1.14$, residual $\mathrm{SE}=0.19$ ).

\section{DISCUSSION}

This study presents the first description of attendance patterns, at-sea movements and diving behaviour of Antarctic fur seals from Bouvetøya. The waters around this isolated island are much less studied than those around other colonies of this important Southern Ocean predator, although recent surveys for benthic invertebrates (Arntz 2006) and notothenoid fish (Jones et al. 2008) have increased our knowledge of this isolated island ecosystem substantially. Similar to other large Antarctic fur seal populations in the Scotia Sea and South Atlantic, krill has been shown to constitute the main prey of fur seals from Bouvetøya (Klages et al. 1999, Kirkman et al. 2000). Recent studies suggest that $\sim 70 \%$ of the global krill stock is concentrated in the Atlantic sector of the Southern Ocean (Atkinson et al. 2008). While most of this krill is found around the Antarctic Peninsula, South Georgia and the Scotia Ridge, high krill abundances have also been recorded around Bouvetøya (Pakhomov 2004). Simulation studies using ocean circulation models suggest that possible pathways of krill advection to Bouvetøya are mainly from the Antarctic Peninsula and the South Sandwich Islands via the Antarctic Circumpolar Current (ACC) and from the Weddell Sea via the northern eastward flow of the Weddell Gyre (Thorpe et al. 2007). The apparent preference for feeding throughout 


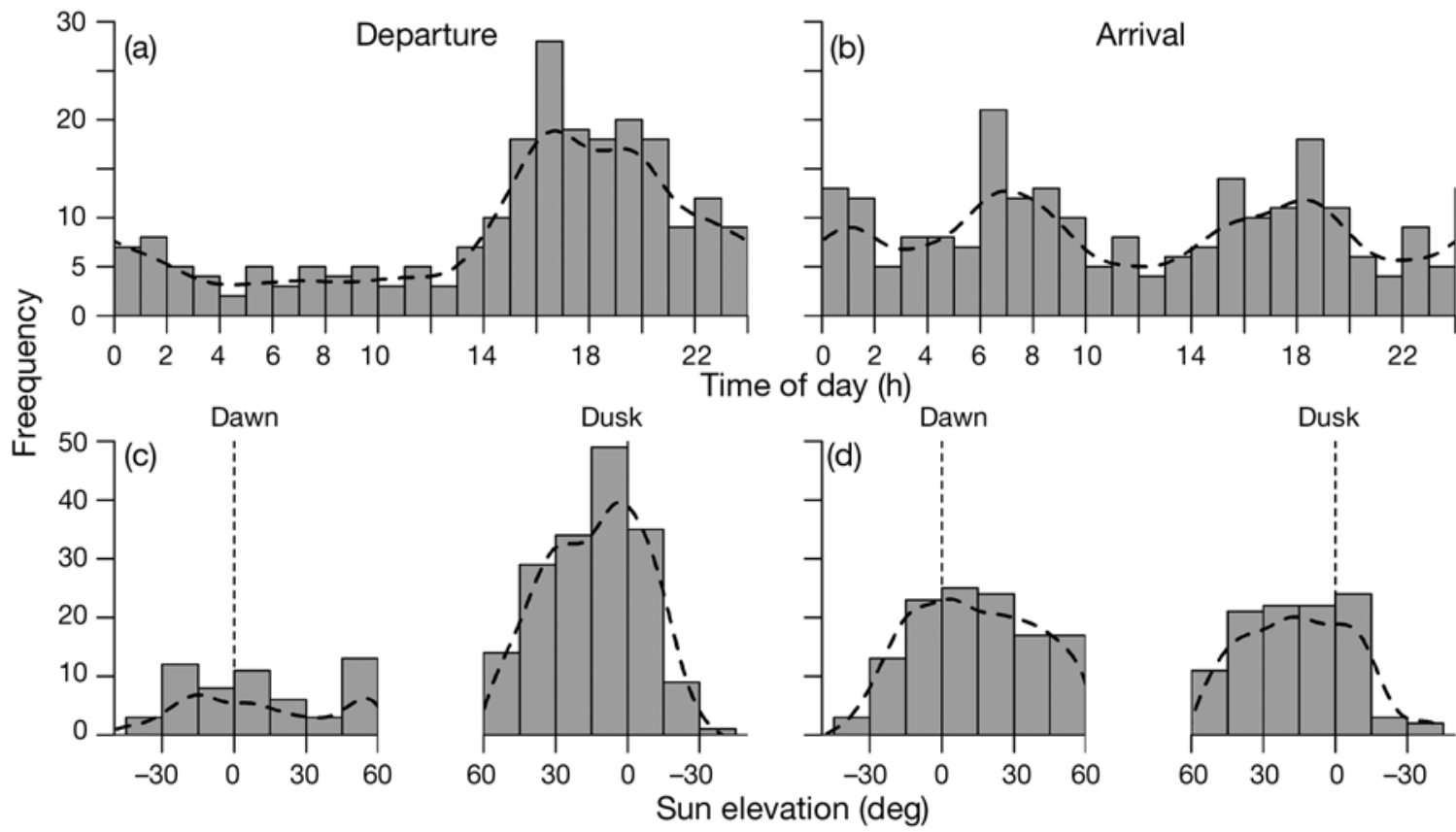

Fig. 4. Arctocephalus gazella. Frequency of $(\mathrm{a}, \mathrm{c})$ departures from, and $(\mathrm{b}, \mathrm{d})$ arrivals to the colony as a function of time of day $(\mathrm{a}, \mathrm{b})$ and solar elevation $(\mathrm{c}, \mathrm{d})$. The histograms for dawn periods are drawn with solar elevations increasing from left to the middle representing the period between midnight and noon, while the histograms for dusk periods are drawn with elevations decreasing from left to right representing noon to midnight. The vertical broken lines in the dawn and dusk histograms therefore represent sunrise and sunset respectively. The fitted dashed curves are local polynomial kernel smoothers with bandwidths of $1 \mathrm{~h}$ and $8^{\circ}$ respectively for time of day and solar elevations
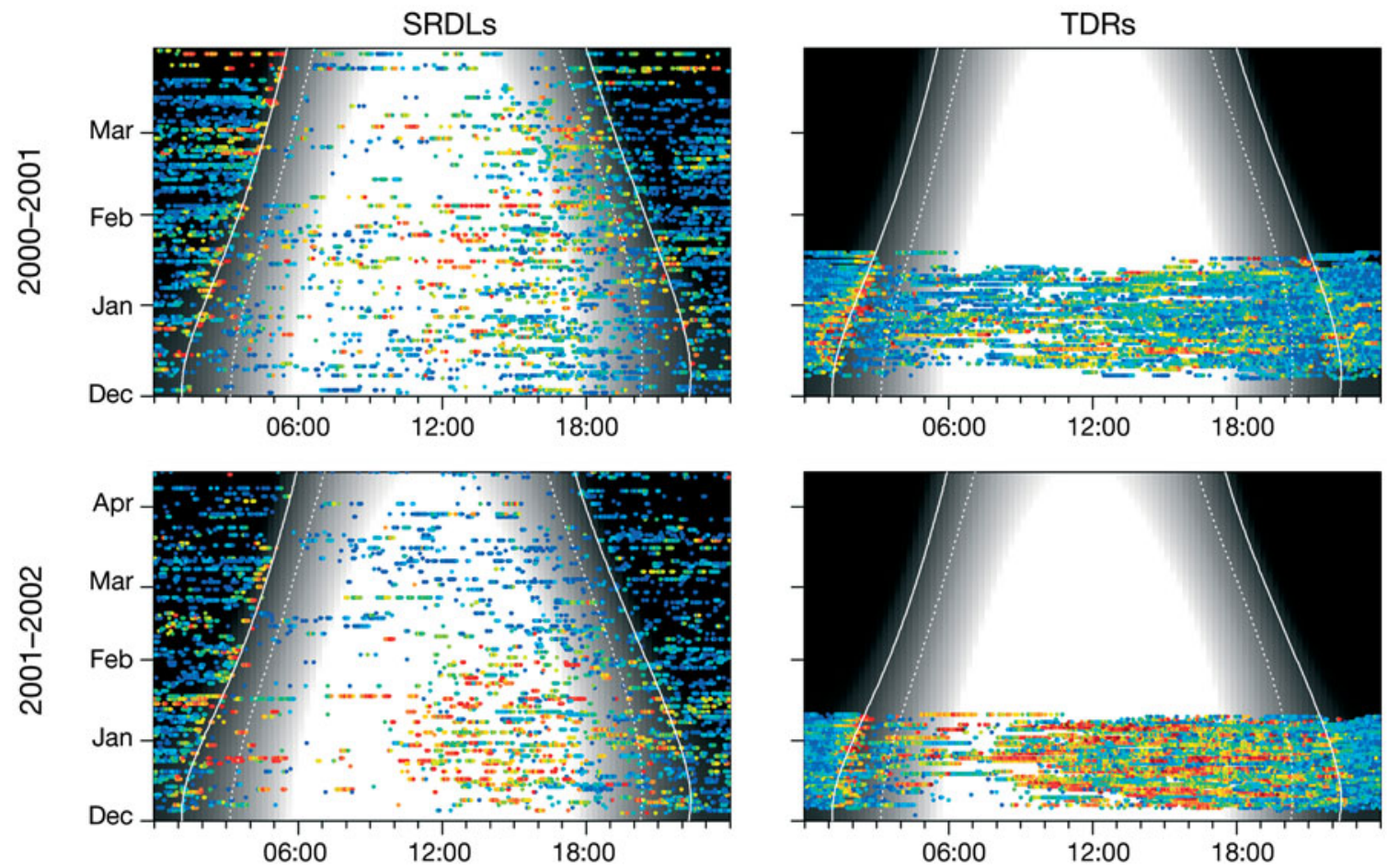

Fig. 5. Image plots of the solar elevation at Bouvetøya during the 2 study periods 2000-2001 (top) and 2001-2002 (bottom), as a function of time of day (horizontal axis) and date (vertical axis), for Antarctic fur seals equipped with satellite relay data loggers (SRDLs; left panels) or Mk6 time depth recorders (TDRs; right panels). The elevation is represented in grey scale to roughly represent light intensity. Solid black areas represent elevations below astronomical twilight (defined as solar elevations $-18^{\circ}$, below which the sun does not contribute to sky illumination). The solid white lines represent solar elevations of $-12^{\circ}$ (nautical twilight), while the dotted white lines represent sunrise and sunset. The overlaid points indicate individual dives, with the colour as a relative index of maximum depth (red $=$ dives of $\sim 100 \mathrm{~m}$; dark blue $=$ dives near the surface) 


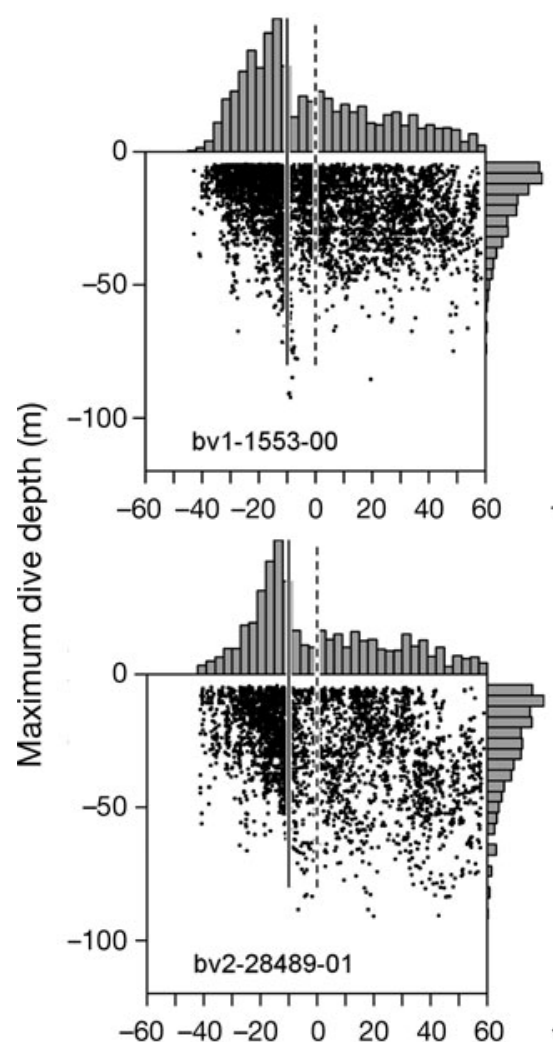

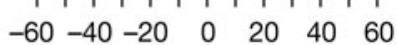
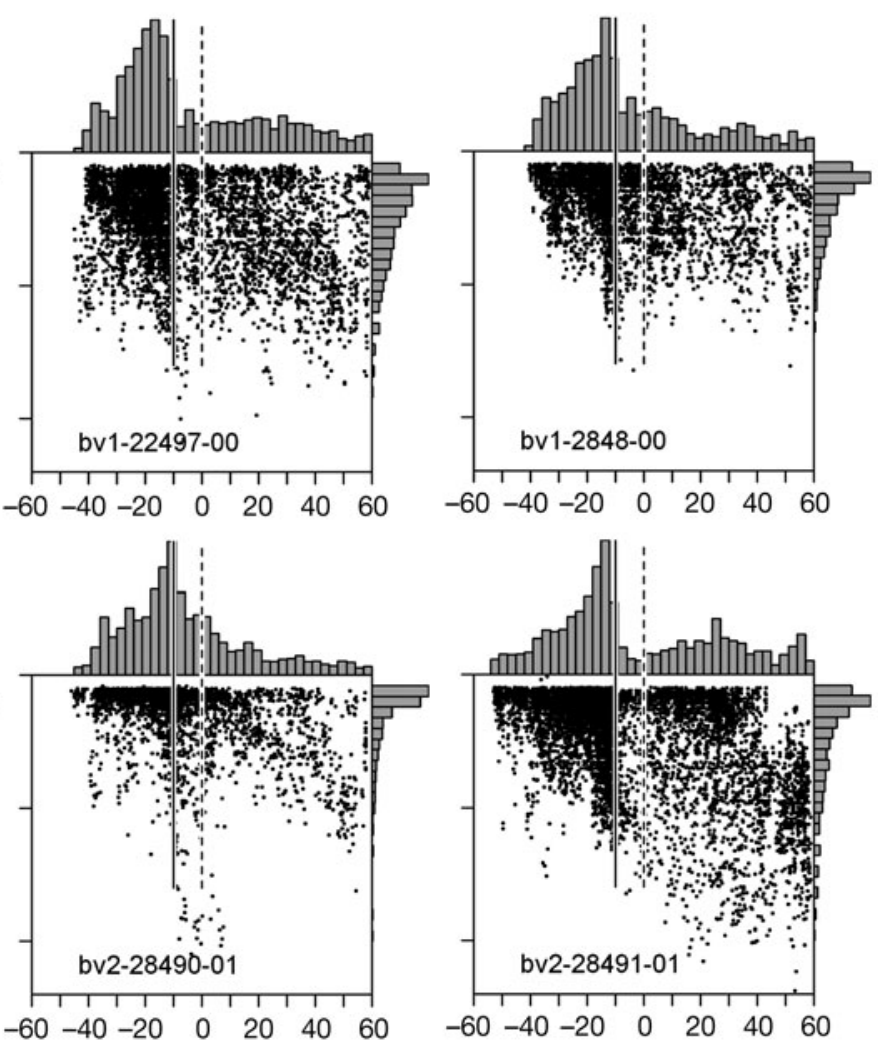

Solar elevation (deg)

Fig. 6. Arctocephalus gazella. Combined scatterplots and histograms of dive frequency and depth as a function of solar elevation. Each point represents the maximum depth reached in each dive performed by Antarctic fur seals equipped with satellite relay data loggers (SRDLs). The top histograms represent the frequency distribution of dives across solar elevations, while the righthand histogram represents the frequency distribution of maximum depths reached. The solid vertical lines represent nautical twilight $\left(-12^{\circ}\right)$ while the broken lines represent sunrise or sunset

the western sector relative to the island may be linked to these likely recruitment processes. Upstream feeding to the west of the island early in the season may target krill swarms as they first become accessible to breeding seals. Changes in mean bearings in the seal paths later in the season may reflect seals tracking krill swarms as they drift with the ACC throughout the summer season. Atkinson et al. (2008) developed an index of mean growth potential of krill based on an empirical growth model combined with food abundance (estimated from chlorophyll a concentration) and sea surface temperature. Large patches of elevated mean growth potential predicted by their model can be seen between the Southern ACC Front (SACCF) and the southern ACC boundary ( $\mathrm{sACCb}$ ) around the position of Bouvetøya.

Time budgets, at-sea movements and diving behaviour of the fur seals in the present study are similar to patterns reported for fur seals from other colonies where krill constitutes their main prey. Most feeding by individuals from Bouvetøya during early to mid-lac- tation occurs within $\sim 100 \mathrm{~km}$ around the island, and is mainly focused in the area to the west of the island. Similar restrictions in feeding range have been described for females at Bird Island during early to mid-lactation (Boyd et al. 2002). During this period there was relatively strong site fidelity displayed by individual seals, and consecutive trips predominantly targeted similar regions. Similar patterns have been described for Antarctic fur seals elsewhere. For instance, Bonadonna et al. (2001) showed that individual seals at Kerguelen tend to travel in similar directions in consecutive trips, but that the range from the colony can differ. Consistencies in mean travel direction within individuals between trips have also been described from Bird Island (e.g. Staniland et al. 2004). While such broad preferences appear to persist between years, modifications occur both throughout the lactation period, probably in response to changing pup demands, and between years in response to changing prey abundance and distribution (McCafferty et al. 1998, Boyd et al. 2002). However, these 

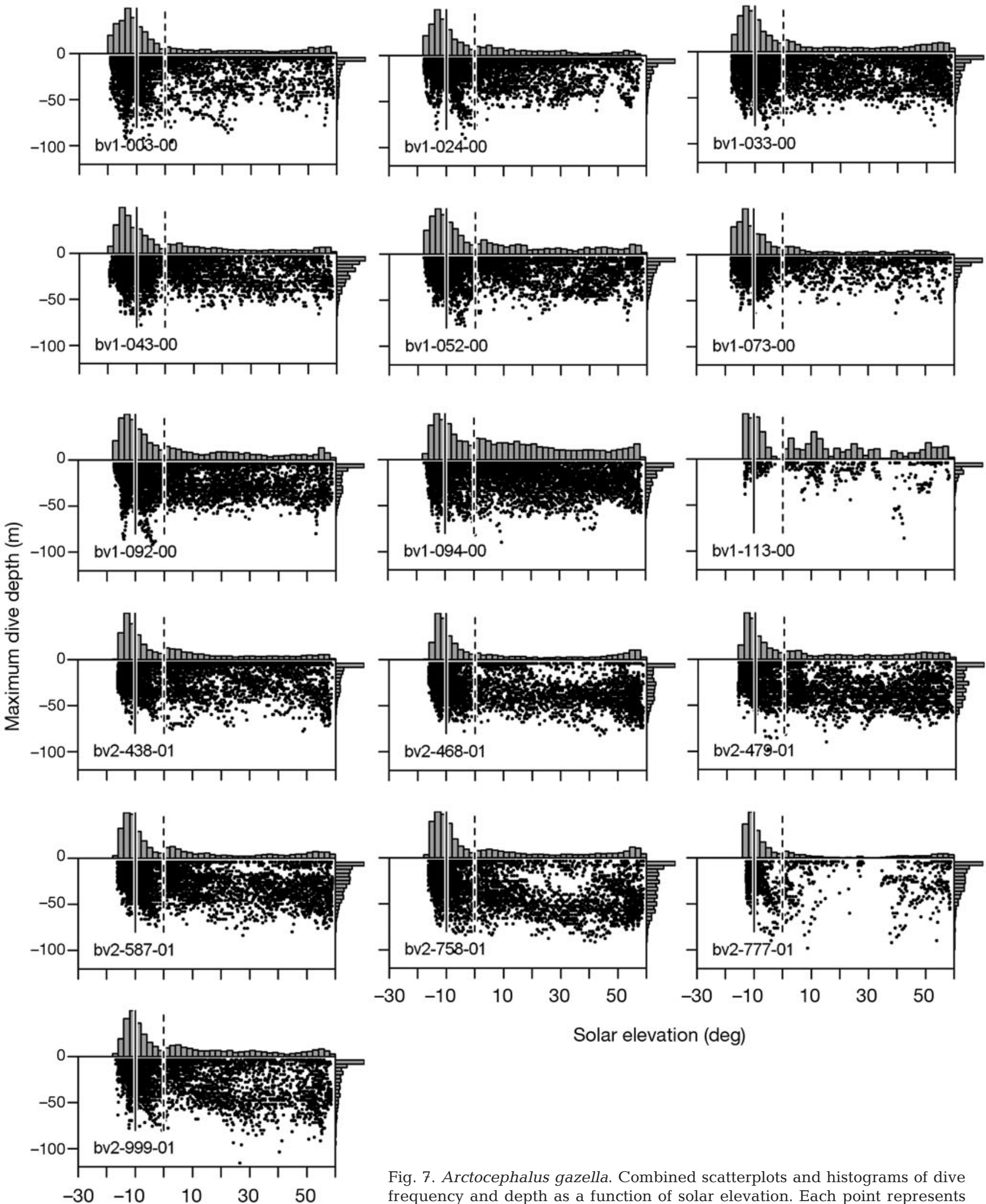

Solar elevation (deg)

Fig. 7. Arctocephalus gazella. Combined scatterplots and histograms of dive frequency and depth as a function of solar elevation. Each point represents the maximum depth reached in each dive performed by Antarctic fur seals

Solar elevation (deg) equipped with Mk6 time depth recorders (TDRs). Further details as in Fig. 6 
Table 4. Arctocephalus gazella. Individual total time budgets over the first 5 to $6 \mathrm{wk}$ of lactation for which both satellite relay data logger (SRDL) and Mk6 time depth recorder (TDR) data were available. Numbers represent percentages of total time of each data record after deleting all non-complete haulout periods and trips

\begin{tabular}{|lccr|}
\hline Seal ID & Haulout & Surface & Diving \\
\hline SRDLs & & & \\
bv1-1553-00 & 26.8 & 64.5 & 8.7 \\
bv1-22497-00 & 32.4 & 55.5 & 12.2 \\
bv1-2848-00 & 38.4 & 54.8 & 6.8 \\
bv2-28489-01 & 36.8 & 51.5 & 11.7 \\
bv2-28490-01 & 36.1 & 61.3 & 2.6 \\
bv2-28491-01 & 37.1 & 51.8 & 11.1 \\
& & & \\
TDRs & & & \\
bv1-003-00 & 28.2 & 62.3 & 9.5 \\
bv1-024-00 & 28.1 & 62.8 & 9.1 \\
bv1-033-00 & 30.0 & 58.0 & 12.0 \\
bv1-043-00 & 44.6 & 46.7 & 8.7 \\
bv1-052-00 & 35.7 & 54.4 & 9.9 \\
bv1-073-00 & 36.6 & 57.6 & 5.8 \\
bv1-092-00 & 28.7 & 59.5 & 11.9 \\
bv1-094-00 & 27.2 & 56.9 & 15.9 \\
bv1-113-00 & 79.9 & 18.1 & 2.0 \\
bv2-438-01 & 37.3 & 50.5 & 12.2 \\
bv2-468-01 & 32.4 & 52.9 & 14.7 \\
bv2-479-01 & 30.5 & 57.7 & 11.8 \\
bv2-587-01 & 25.8 & 61.2 & 13.0 \\
bv2-758-01 & 32.5 & 54.8 & 12.7 \\
bv2-777-01 & 27.9 & 63.4 & 8.6 \\
bv2-999-01 & 32.0 & 59.8 & 8.3 \\
\hline
\end{tabular}

modifications appear to mostly affect the distance travelled, while the general directional preferences are more persistent. This may be explained partly by the existence of colony-specific directional preferences (Boyd et al. 2002). While we found relatively strong support for directional consistency within individuals, the preference for feeding throughout the western sector was not as persistent as patterns shown elsewhere. It is possible that the small size of Bouvetøya and the fact that the great majority of breeding seals are found at the Nyrøysa colony prevents the establishment of any colony-specific segregation in foraging areas.

Several studies have suggested the existence of a few more or less distinct feeding strategies by lactating females, characterised by distance from the colony and depth of diving (Bonadonna et al. 2001, Staniland et al. 2004). These strategies are to a large extent influenced by the existence of extensive areas of continental shelf around the colonies studied, one common strategy being characterised by a strong preference for feeding along the shelf edge. Bouvetøya completely lacks any continental shelf, and it is possible that the distribution of krill is more influenced by prevailing open-ocean currents, and that the establishment of elevated krill abundances in association with e.g. shelf frontal struc-

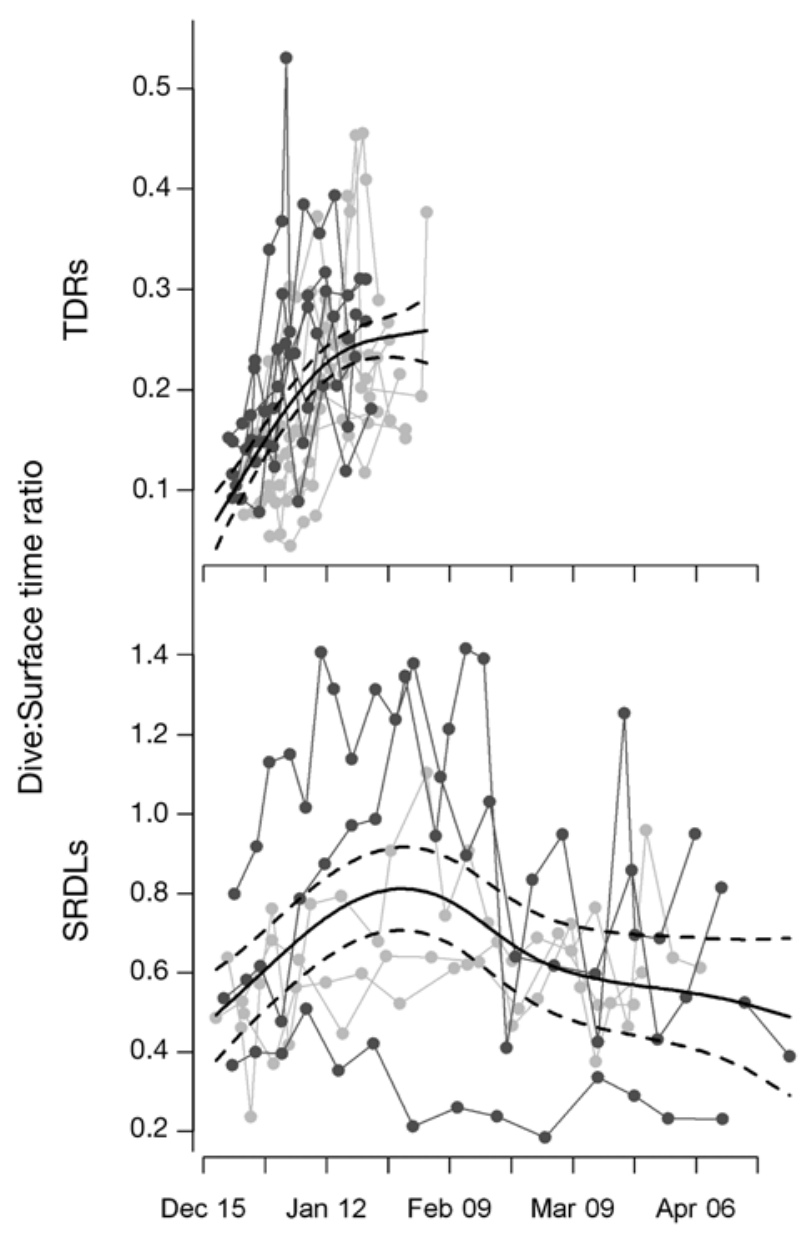

Fig. 8. Arctocephalus gazella. The ratio of time spent diving to time spent at the surface, expressed as totals during each trip for Antarctic fur seals equipped with Mk6 time depth recorders (TDRs; top panel) or satellite relay data loggers (SRDLs; bottom panel). The fitted curves represent predictions (mean $\pm \mathrm{SE}$ ) from generalised additive mixed-effects models (GAMM) of dive:surface ratio as a function of date. Note that the estimates of dive:surface ratio from TDR data and SRDL data are not directly comparable due to the summarised nature of the SRDL data (see 'Note on different data types' for further details). The main point of this figure is to highlight the changes over time

tures is not possible. Nevertheless, we did find some indications of different feeding strategies. One individual in particular (bv1-2848-00) appeared to alternate between regular trips to areas $\sim 100 \mathrm{~km}$ from the colony and shorter trips to within $30 \mathrm{~km}$ from the island. It is of course impossible with our limited data to even speculate as to whether this is a response to changing pup requirements (e.g. a pup in poor condition may require more frequent attendance and milk input to survive) or to some environmental fluctuations.

The temporal behavioural patterns, in terms of attendance cycles and diving, are also likely a direct response to krill behaviour and distribution. For instance, 
the timing of arrivals and departures by females to and from the colony appears to be linked to solar elevation, and the tendency of mothers to leave the island in the afternoon and evening hours is almost certainly a response to the vertical migration of krill around sunset into surface waters where they are more accessible to the seals. The links between vertical migration of krill and the diurnal variations in fur seal diving activity and depth has been well established in the literature (Croxall et al. 1985, Fraser et al. 1989, Hunt et al. 1992), and the present study demonstrates that Bouvetøya fur seals follow the typical, mostly nocturnal, diving behaviour. Higher night-time dive frequencies can sometimes simply be a consequence of seals making a large number of short-duration shallow dives rather than a few long-duration deep dives. However, all of our seals displayed a gradual increase in dive frequency during the morning hours to a maximum around nautical twilight, coinciding with gradual increases in dive depths and durations as the krill migrates downwards when ambient light levels increase (Fig. 6 \& 7).

The lowest dive frequencies were observed following sunrise, before seals again increased their dive effort during the afternoon (Fig. 5). Afternoon dives generally targeted depths of 50 to $80 \mathrm{~m}$, with some females reaching $>100 \mathrm{~m}$. These depths correspond to the known depth range of krill during daytime (Demer \& Hewitt 1995). It is possible that elevated krill densities during the day are found in a narrow layer of optimal conditions beneath the photic zone but above the thermocline, allowing deep-diving daytime feeders to benefit from higher prey densities. Considering the substantially higher effort involved in diving to greater depths in relation to the amount of time potentially available at the bottom of the dive, but also allowing for the potentially higher prey densities at these depths, deep daytime dives may have an important influence on the overall energy budgets of individual females.

Our study also demonstrates the importance of following specific individuals through lactation in order to understand the individual dynamics of lactation strategies. The importance of this sort of individualspecific data has been widely acknowledged, but results from detailed long-term tracking of specific individuals are nevertheless relatively rare in the literature. CEMP standard procedures frequently use data from only the 6 first feeding trips (CCAMLR 2004) to limit any biases due to individual variation. While this standardisation facilitates annual comparisons of reproductive success in relation to prey availability, it does not allow for the assessment of the role that seasonal dynamics in prey availability may have on fur seal behaviour during lactation, and the examination of the possibility that seals may temporally adjust their reproductive expenditure according to these dynamics. Such seasonal dynamics may change dramatically from year to year, so focusing only on the earliest period of lactation may bias the estimates of annual fluctuations in breeding success. Seasonal variations in attendance patterns and reproductive energetics are known to be influenced by several factors, some of which will be driven directly by the environment while others are mediated through the energetic state of the mother as well as the pup.

In summary, the present study provides the first information about the at-sea behaviour and time budgets of a krill predator breeding at Bouvetøya. We have shown that longitudinal records for individuals conform broadly to the established view of the behaviour of this well-studied pinniped from shorter crosssectional records. We have also highlighted large seasonal variations, which have also been described elsewhere. We suggest that much more detailed information about the various aspects of this variation, and about the links between environmental fluctuations, feeding strategies and reproductive success, are needed. Such data are difficult or even impossible to obtain from remote and rugged field sites such as Nyrøysa. It may be possible to develop models based on relatively basic data collected on an ad hoc basis that may allow us to address these issues of seasonal variations. However, such models will have to be tested on more rigorously collected data prior to their application to simpler data sets.

Acknowledgements. This study was carried out as part of the 2000-2001 and 2001-2002 Norwegian Antarctic Research Expeditions (NARE) financed by the Norwegian Polar Institute and the Norwegian Agency for Development Cooperation (NORAD). Additional logistic support was kindly provided by the South Africa National Antarctic Program (SANAP) and the Alfred Wegener Institute for Polar and Marine Research (AWI). We thank the captains and crews of the RV 'Polarstern', the RV 'Lance' and the SA 'Agulhas' for transportation to and from the island, and the personnel of the Canadian Helicopter Company Ltd. and Court Helicopters Ltd. for cargo and personnel transfer between the ships and the island. We also thank B. Harck, L. Krag, D. Keith, C. Brady and B. Flascas for valuable assistance in the field.

\section{LITERATURE CITED}

Arntz WE (2006) Bouvet Island: a stepping stone in the Southern Ocean? Polar Biol 29:81-82

Atkinson A, Siegel V, Pakhomov EA, Rothery P and others (2008) Oceanic circumpolar habitats of Antarctic krill. Mar Ecol Prog Ser 362:1-23

> Beauplet G, Dubroca L, Guinet C, Cherel Y, Dabin W, Gagne C, Hindell M (2004) Foraging ecology of subantarctic fur seals Arctocephalus tropicalis breeding on Amsterdam Island: seasonal changes in relation to maternal characteristics and pup growth. Mar Ecol Prog Ser 273:211-225

Bonadonna F, Lea MA, Dehorter O, Guinet C (2001) Foraging 
ground fidelity and route-choice tactics of a marine predator the Antarctic fur seal Arctocephalus gazella. Mar Ecol Prog Ser 223:287-297

Boyd IL (1998) Time and energy constraints in pinniped lactation. Am Nat 152:717-728

Boyd IL (1999) Foraging and provisioning in Antarctic fur seals: interannual variability in time-energy budgets. Behav Ecol 10:198-208

Boyd IL, Lunn NJ, Barton T (1991) Time budgets and foraging characteristics of lactating Antarctic fur seals. J Anim Ecol 60:577-592

Boyd IL, Staniland IJ, Martin AR (2002) Distribution of foraging by female Antarctic fur seals. Mar Ecol Prog Ser 242: 285-294

CCAMLR (2004) CCAMLR ecosystem monitoring programme: standard methods for monitoring studies. CCAMLR, Hobart

Committee on Marine Mammals (1967) Standard measurements of seals. J Mammal 48:459-462

> Croxall JP, Everson I, Kooyman GL, Ricketts C, Davis RW (1985) Fur seal diving behaviour in relation to vertical distribution of krill. J Anim Ecol 54:1-8

David JHM, Meyer MA, Best PB (1990) The capture, handling and marking of free-ranging adult South-African (Cape) fur seals. S Afr J Wildl Res 20:5-8

Demer DA, Hewitt RP (1995) Bias in acoustic biomass estimates of Euphausia superba due to diel vertical migration. Deep-Sea Res 42:455-475

Fedak MA, Lovell P, Grant SM (2001) Two approaches to compressing and interpreting time-depth information as collected by time-depth recorders and satellite-linked data recorders. Mar Mamm Sci 17:94-110

Fraser WR, Pitman RL, Ainley DG (1989) Seabird and fur seal responses to vertically migrating winter krill swarms in Antarctica. Polar Biol 10:37-41

Goldsworthy SD (1995) Differential expenditure of maternal resources in Antarctic fur seals, Arctocephalus gazella, at Heard Island, southern Indian Ocean. Behav Ecol 6: $218-228$

Gu C, Wahba G (1991) Minimizing GCV/GML scores with multiple smoothing parameters via the Newton method. SIAM J Sci Stat Comput 12:383-398

Hill SL, Reid K, Thorpe SE, Hinke J, Watters GM (2007) A compilation of parameters for ecosystem dynamics models of the Scotia Sea - Antarctic Peninsula region. CCAMLR Sci 14:1-25

Hofmeyr GJG, Krafft BA, Kirkman SP, Bester MN, Lydersen C, Kovacs KM (2005) Population changes of Antarctic fur seals at Nyrøysa, Bouvetøya. Polar Biol 28:725-731

Houston AI, Stephens PA, Boyd IL, Harding KC, McNamara JM (2007) Capital or income breeding? A theoretical model of female reproductive strategies. Behav Ecol 18:241-250

Hunt GL Jr, Heinemann D, Everson I (1992) Distributions and predator-prey interactions of macaroni penguins, Antarctic fur seals, and Antarctic krill near Bird Island, South Georgia. Mar Ecol Prog Ser 86:15-30

Jammalamadaka SR, SenGupta A (2001) Topics in circular statistics, Section 1.3. World Scientific Press, Singapore

Jones CD, Anderson ME, Balushkin AV, Duhamel G and others (2008) Diversity, relative abundance, new locality records and population structure of Antarctic demersal fishes from the northern Scotia Arc islands and Bouvetøya.

Editorial responsibility: Andrew Brierley, St. Andrews, UK
Polar Biol 31:1481-1497

Kirkman SP, Wilson W, Klages NTW, Bester MN, Isaksen K (2000) Diet and estimated food consumption of Antarctic fur seals at Bouvetøya during summer. Polar Biol 23: $745-752$

Kirkman SP, Hofmeyr GJG, Bester MN, Isaksen K (2001) Counts of southern elephant seals, Mirounga leonina, at Bouvet Island. Polar Biol 24:62-65

Klages NTW, Hofmeyr GJG, Gjertz ILB (1999) Prey of Antarctic fur seals at Bouvetøya, Southern Ocean. Polar Rec 35: 255-257

Kock CH (2000) Understanding CCAMLR's approach to management. CCAMLR, Hobart. www.ccamlr.org/pu/E/ e_pubs/am/p7.htm

Lewin-Koh NJ, Bivand R (eds) (2008) maptools: tools for reading and handling spatial objects. http://cran.r-project.org/ web/packages/maptools/index.html

Lunn NJ, Boyd IL, Barton T, Croxall JP (1993) Factors affecting the growth rate and mass at weaning of Antarctic fur seals at Bird Island, South Georgia. J Mammal 74:908-919

McCafferty DJ, Boyd IL, Walker TR, Taylor RI (1998) Foraging responses of Antarctic fur seals to changes in the marine environment. Mar Ecol Prog Ser 166:285-299

McConnell BJ, Chambers C, Fedak MA (1992) Foraging ecology of southern elephant seals in relation to the bathymetry and productivity of the Southern Ocean. Antarct Sci 4:393-398

Meeus J (1991) Astronomical algorithms. Willmann-Bell, Richmond, VA

Pakhomov EA (2004) Salp/krill interactions in the eastern Atlantic sector of the Southern Ocean. Deep-Sea Res II 51: 2645-2660

Pinheiro JC, Bates DM (2002) Mixed-effects models in S and S-PLUS. Springer-Verlag, New York, NY

R Development Core Team (2008) R: a language and environment for statistical computing. R Foundation for Statistical Computing, Vienna. www.R-project.org

Reid K, Croxall JP, Briggs DR, Murphy EJ (2005) Antarctic ecosystem monitoring: quantifying the response of ecosystem indicators to variability in Antarctic krill. ICES J Mar Sci 62:366-373

Staniland IJ, Reid K, Boyd IL (2004) Comparing individual and spatial influences on foraging behaviour in Antarctic fur seals Arctocephalus gazella. Mar Ecol Prog Ser 275: 263-274

> Thorpe SE, Murphy EJ, Watkins JL (2007) Circumpolar connections between Antarctic krill (Euphausia superba Dana) populations: investigating the roles of ocean and sea ice transport. Deep-Sea Res Part I 54:792-810

Trillmich F, Weissing FJ (2006) Lactation patterns of pinnipeds are not explained by optimization of maternal energy delivery rates. Behav Ecol Sociobiol 60:137-149

US Naval Observatory (2007) Definitions from the US Astronomical Applications Dept (USNO). http//aa.usno.navy. mil/faq/docs/RST_defs.php

Wand M, Ripley BD (2005) KernSmooth: functions for kernel smoothing for Wand \& Jones (S original by Matt Wand. $\mathrm{R}$ port by Brian Ripley). http://cran.r-project.org/web/ packages/KernSmooth/index.html

Wood SN (2004) Stable and efficient multiple smoothing parameter estimation for generalized additive models. J Am Stat Assoc 99:673-686

Submitted: October 10, 2008; Accepted: March 23, 2009

Proofs received from author(s): June 8, 2009 